\title{
Variation among colonies in breeding success and population trajectories of wandering albatrosses Diomedea exulans at South Georgia
}

\author{
Carola Rackete $^{1,4} \cdot$ Sally Poncet ${ }^{2} \cdot$ Stephanie D. Good ${ }^{3} \cdot$ Richard A. Phillips $^{4} \cdot$ Ken Passfield $^{2} \cdot$ Philip Trathan $^{4}(\mathbb{D}$
}

Received: 11 November 2019 / Revised: 24 November 2020 / Accepted: 1 December 2020 / Published online: 4 January 2021

(c) Crown 2021

\begin{abstract}
The wandering albatross, Diomedea exulans, is a globally threatened species breeding at a number of sites within the Southern Ocean. Across the South Georgia archipelago, there are differences in population trends even at closely located colonies. Between 1999 and 2018 the largest colony, at Bird Island, declined at 3.01\% per annum, while in the Bay of Isles, the decline was $1.44 \%$ per annum. Using mean demographic rates from a 31-year study at Bird Island and an 11-year study of breeding success at Prion Island in the Bay of Isles in a VORTEX model, we show that differences in breeding success do not fully explain observed differences in population trends. Other potential contributing factors are differential use of foraging areas, with possible knock-on effects on adult body condition, provisioning rate and breeding success, or on bycatch rates of adults or immatures.
\end{abstract}

Keywords Wandering albatross $\cdot$ Breeding success survival $\cdot$ Inter-colony variation

\section{Introduction}

Understanding variation in demography and ecology of seabirds is important in terms of testing life-history theory and for assessing population dynamics, particularly with regard to conservation management of threatened species (Hunt and He 2019).

The wandering albatross Diomedea exulans is listed as Vulnerable (BirdLife International 2018) by the International Union for Conservation of Nature (IUCN), with the population decline attributed largely to incidental mortality (bycatch) in longline fisheries (Rolland et al. 2010; Pardo

Philip Trathan

pnt@bas.ac.uk

1 Biosciences, Edge Hill University, St Helen's Road, Ormskirk L39 4QP, UK

2 South Georgia Surveys, Falkland Islands, PO Box 538, Stanley FIQQ 1ZZ, UK

3 Centre for Ecology \& Conservation, University of Exeter, Cornwall campus, Penryn TR10 9EF, UK

4 British Antarctic Survey, Natural Environment Research Council, High Cross, Madingley Road, Cambridge CB3 OET, UK et al. 2017). The impacts of fisheries are severe because the wandering albatross has an extreme life history even in contrast to other seabirds, characterised by a long life span under natural circumstances, biannual breeding if successful, and high breeding success, all of which influence population dynamics (Weimerskirch and Jouventin 1987; Pardo et al. 2017).

Wandering albatrosses are well monitored globally, and breeding populations in the southwest Indian Ocean at Kerguelen, Crozet and the Prince Edward Islands have been recovering from previous fisheries-related declines since the mid-1980s, a situation mainly attributed to changes in the degree of overlap with vessels (Weimerskirch et al. 2018). Moreover, variation between colonies in population trends has been documented on the Crozet Archipelago (Weimerskirch et al. 2018), where tracking data have shown differences in the use of foraging areas between colonies (Weimerskirch et al. 1993) which may expose birds to different fisheries and mortality risks. In contrast, wandering albatrosses at South Georgia (South Atlantic) have shown a continued population decline since the 1960s and so have been identified as one of nine global High Priority populations for conservation by the Agreement on the Conservation of Albatrosses and Petrels (ACAP) (ACAP 2017). At South Georgia, the last 
archipelago-wide census of wandering albatrosses (Fig. 1) carried out in summer 2014/15 showing an overall decline of $1.76 \%$ breeding pairs per annum since the previous census in 2004/05, with declines varying between colonies (Poncet et al. 2017). At the largest colony, Bird Island, a longitudinal study of demographic rates between 1972 and 2012 determined that low adult survival was the main driver of decline. Further, that low juvenile survival became increasingly important over time, resulting in reduced recruitment which was not balanced by a slight increase in breeding success (Pardo et al. 2017).

Although there have been many studies of variation in demographic parameters of seabirds at single colonies (e.g. Mauck et al. 2004; Oro et al. 2010; Pardo et al. 2017), there has been less exploration of variation between colonies, generally because of a lack of suitable data (but see, e.g. Frederiksen et al. 2007; Sandvik et al. 2012; Descamps et al. 2017). However, at South Georgia, annual monitoring of breeding numbers and success has been carried out at the Bay of Isles in addition to Bird Island.
Here, we compare population trajectories and breeding success between these areas, separated by approximately $50 \mathrm{~km}$. We model the population dynamics with the aim of improving understanding of inter-colony variation in population trends at South Georgia. We hypothesize that a difference in breeding success is the main driver of the observed disparity in population trends, and discuss the results in the context of other potential contributing factors.

\section{Materials and methods}

\section{Study sites and data collection}

The South Georgia Archipelago holds $17.64 \%$ of the global wandering albatross breeding population (Phillips et al. 2016), with the last census in 2014/5 giving an estimate of 1278 breeding pairs in total (Poncet et al. 2017); hereafter, breeding seasons will be referred to as the year in which the chicks fledge, in this case 2015 . Bird Island $\left(54^{\circ} 00^{\prime} \mathrm{S}\right.$,

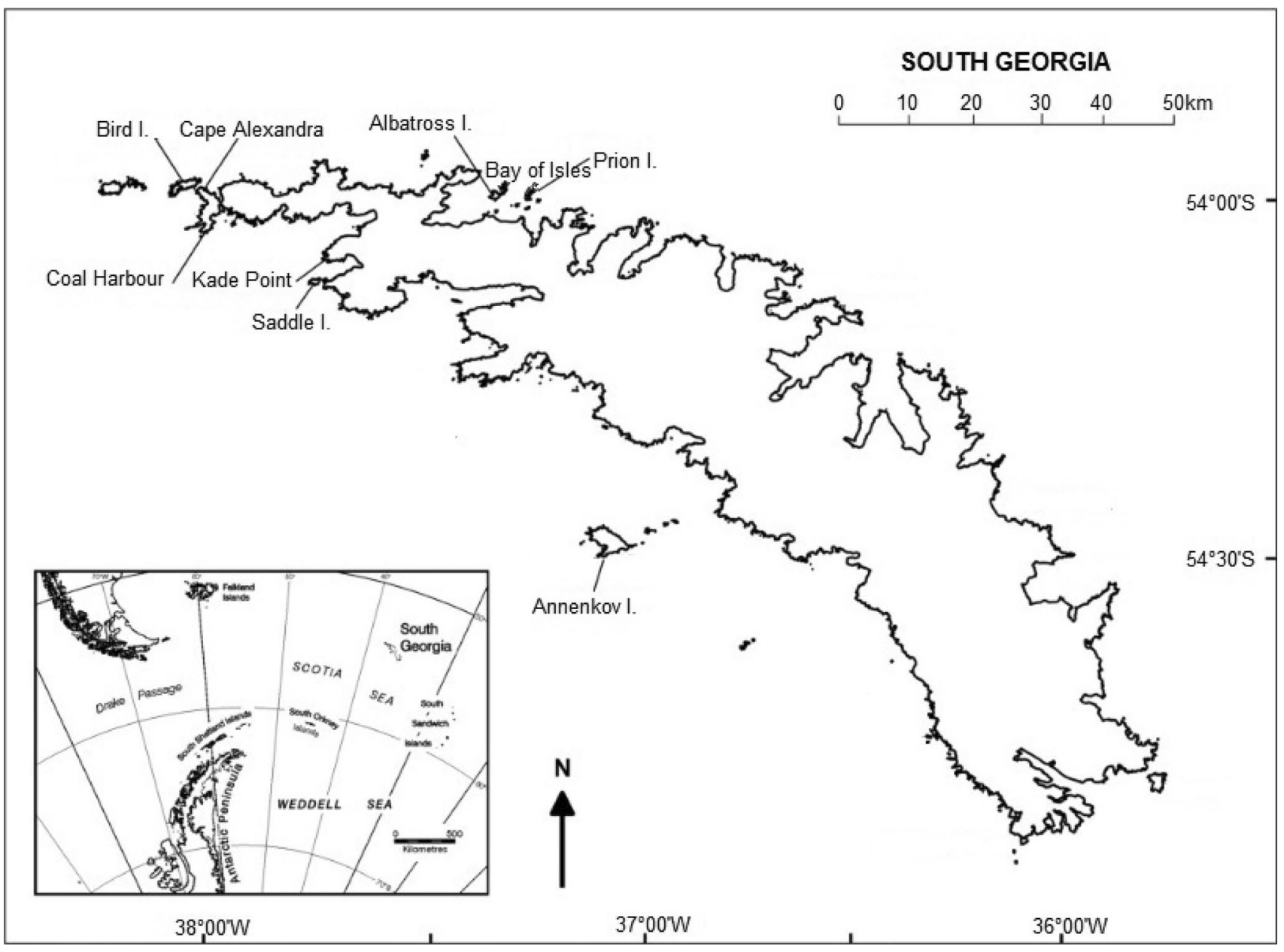

Fig. 1 Locations of sizeable breeding sites (>15 pairs) of wandering albatross on South Georgia with inset map of South Georgia and the Scotia Sea, adapted from Poncet et al. (2006) 
$38^{\circ} 03^{\prime} \mathrm{W}$ ) held $60.41 \%$ of the breeding pairs at South Georgia while the Bay of Isles colonies represented $16.36 \%$ (Poncet et al. 2017), of which Albatross Island $\left(54^{\circ} 01^{\prime} \mathrm{S}\right.$, $\left.37^{\circ} 20^{\prime} \mathrm{W}\right)$ and Prion Island $\left(54^{\circ} 01^{\prime} \mathrm{S}, 37^{\circ} 15^{\prime} \mathrm{W}\right)$ together held $80-85 \%$ of the total. In addition to the census in $2014 / 15$, we also use breeding pair counts from 1984 and 2004, including from five other breeding sites at South Georgia that held $>15$ pairs in 2004: Annenkov Island, Saddle Island, Cape Alexandra, Kade Point and Coal Harbour (Poncet et al. 2006, 2017).

Annual monitoring of breeding pairs at Prion Island and Albatross Island began in 1999, and of breeding success at Prion Island in 2007. At Bird Island, annual monitoring of demographic parameters, including breeding success began in 1980 (Pardo et al. 2017). The number of breeding pairs was estabilished by counting incubating adults between the end of December and early January, after the peak of egg laying. Counts of breeding pairs at Albatross Island and Prion Island are pooled and referred to as "Bay of Isles " as there was no difference in trends between these two sites (results not shown). Breeding success was calculated as the proportion of eggs that resulted in a well-grown chick. On Prion Island, breeding success was estimated by counting chicks shortly before fledging, between the middle of October and early November, while breeding success at Bird Island was based on chick survival until 1 November. However, $<1 \%$ of chicks at Bird Island die during October (British Antarctic Survey, unpublished data), and therefore, no correction factor was applied. We used adult and juvenile survival, return and breeding probability from the long-term mark-recapture study carried out at Bird Island according to Pardo et al. (2017).

\section{Statistical analyses}

Statistical tests were carried out in $\mathrm{R}$ version 3.5.0 ( $\mathrm{R}$ CORE team 2018). We compared linear models of breeding pair counts at the Bay of Isles and Bird Island between 1999 and 2018 using an analysis of variance (ANOVA).

To test for breakpoints in population trends over the study period, we fitted segmented piecewise regression models for each site using the R package "segmented" (Muggeo 2008) and tested for significant differences in the slopes of the segments using a Davies Test. We compared trends at Albatross and Prion, and Bird Island, with those at the other sites (Annenkov Island, Saddle Island, Cape Alexandra, Kade Point and Coal Harbour). Breeding success at Bird Island was compared to Prion Island by Student's t test, using data from 2007 to 2018.

Population trends were modelled for Prion Island and Bird Island using the Population Viability Analysis (PVA) software VORTEX v10 (Lacy and Pollack 2014). PVA models provide a means of understanding the influence of differences in demographic rates on the growth or decline of populations (Hamilton and Moller 1995). The VORTEX program simulates the effects of deterministic forces as well as stochastic events using Monte-Carlo methods (Lacy et al. 2018). To obtain key demographic parameters to populate our model, we first used GetData software to extract values for adult survival (AS), juvenile survival (JS) and percent females breeding (FB) (return probability * breeding probability) from estimated vital rates for wandering albatross (Fig. 1) in Pardo et al. 2017. We then ran bootstrapping (1000 replicates) from the sample of values for years 1981 to 2012 using "boot" function in R (Table 1). Mean and 95\% Confidence Intervals were calculated from the distributions. Age at first breeding was set at 10 following Pardo et al. (2017), as this was the age that gave the best model fit.

We applied the VORTEX sensitivity test function to randomly sample the values from the bootstrapped distribution of each parameter (adult mortality, juvenile mortality and percent breeding females) for the population models. The model was run 1000 times each for Bird Island (breeding success $72 \%$ ) and Prion Island (breeding success $83 \%$ ). The main output variable tracked was the population growth rate (r). We applied the Shapiro-Wilk test to the $r$ values from each model and determined that the data were normally distributed. We then applied a Welch 2 sample $t$ test to determine if there was a significant difference in the mean values from $r$ modelled from each population.

Annual fluctuations in birth and death rates due to environmental variation were included for each parameter, assuming a standard deviation of $10 \%$, which is similar to observed variability in Pardo et al. (2017) and produced stable model outputs. All values are given as means \pm standard deviation (SD).

\section{Results}

Between 1999 and 2018, the number of breeding pairs of wandering albatrosses at Albatross Island and Prion Island declined from 220 to 167 ( $-24.09 \%$ overall; equivalent to $-1.44 \%$ per annum) (Fig. 2). Over the same period, the number of breeding pairs at Bird Island declined from 1182 to 661 ( $-44.08 \%$ overall; equivalent to $-3.01 \%$ per annum).

Table 1 Results from bootstrapping estimated demographic rates $(R=1000)$ for adult survival, juvenile survival and proportion of females breeding for years 1981-2012 from Pardo et al. 2017, Fig. 1

\begin{tabular}{lll}
\hline Demographic parameter & Mean & $95 \%$ CI \\
\hline Adult survival (AS) & 0.94 & $0.93,0.95$ \\
Juvenile survival (JS) & 0.85 & $0.80,0.89$ \\
Proportion of females breeding (FB) & 0.45 & $0.43,0.48$ \\
\hline
\end{tabular}



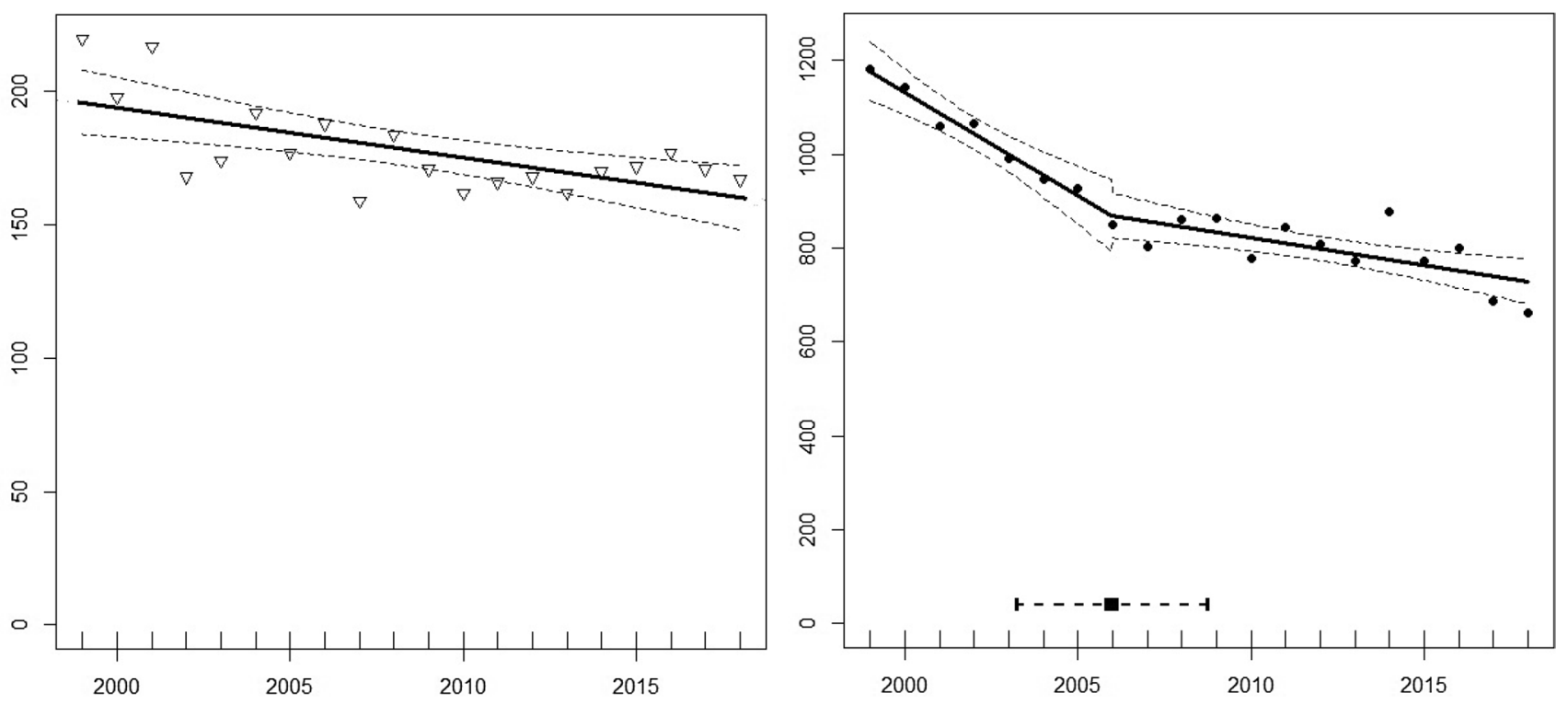

Fig. 2 Changes in numbers of breeding pairs of wandering albatrosses at Bay of Isles (left) and Bird Island (right) between 1999 and 2018. Linear regressions displayed incl. $95 \%$ confidence intervals

The linear models indicated that these trends differed significantly between the two regions (ANOVA, $F_{1}=34.41$, $p<0.0001)$. The decline of breeding pairs at Bird Island showed a single breakpoint in $2006\left( \pm 1.3\right.$ years, $R^{2}=0.91$, $p<0.0001$ ), whereas the model for Albatross and Prion indicated a single breakpoint in $2002\left( \pm 1.0\right.$ year, $R^{2}=0.61$, $p=0.01$ ). For Bird Island, the slopes of the two segments ( -43.97 before and -11.67 after the breakpoint) differed significantly (Davies Test, $(p=0.04)$ indicating a more rapid decline before 2006, whereas there was no significant difference between the slopes in the model for Albatross and Prion islands (Davies Test, $p=0.80$ ).

Based on the archipelago-wide censuses, the number of breeding pairs in the Bay of Isles decreased by $-27.37 \%$ between 1984 and 2015, whereas numbers at all other sites with $>15$ breeding pairs declined more rapidly (ranging from $-39.60 \%$ at Cape Alexandra to $-76.61 \%$ decline at Kade Point). The only site where the decline was less than at Albatross and Prion was the small colony at Coal Harbour (Table 2).

Breeding success was significantly higher at Prion Island $(83.27 \pm 3.64 \% ; n=11)$ than at Bird Island $(72.00 \pm 5.27 \%$; $n=11$ ) between 2007 and 2018 (Student's $t$ test, $t_{18}=-5.84$, $p=<0.0001$.

In the VORTEX output from the population model (Table 3), we found a significant difference in modelled mean exponential growth rate ( $\mathrm{r}$ ) between the two populations (Welch 2 sample $t$ test, $t_{1999.9}=-21.742, p<0.0001$ ). This supports the hypothesis that differences in breeding success partly explain the contrasting growth rate between the populations. However, the estimated annual population
Table 2 Numbers of breeding pairs and trends of wandering albatrosses in different areas at South Georgia with $>15$ breeding pairs. Data from Poncet et al. (2006, 2017)

\begin{tabular}{lrrrrrr}
\hline Breeding Area & \multicolumn{3}{c}{ Breeding season } & & \multicolumn{3}{c}{ Population change (\%) } \\
\cline { 2 - 3 } \cline { 7 - 7 } \cline { 6 - 7 } & 1984 & 2004 & 2015 & & $1984-2004$ & $2004-2015$ \\
\hline Bay of Isles & 285 & 236 & 207 & & -0.27 & -0.12 \\
Bird Island & 1366 & 948 & 772 & & -0.43 & -0.19 \\
Annenkov Island & 264 & 193 & & -0.27 & \\
Saddle Island & 53 & 40 & 32 & & -0.40 & -0.20 \\
Cape Alexandra & 57 & 40 & 35 & -0.39 & -0.13 \\
Kade Point & 41 & 23 & 10 & -0.76 & -0.57 \\
Coal Harbour & 19 & 16 & 18 & -0.05 & 0.13 \\
\hline
\end{tabular}

trends according to the model input parameters would be $-1.37 \%$ and $-0.79 \%$ for Bird Island and the Bay of Isles, respectively, and hence, other factors must also be contributing to the steeper observed declines.

\section{Discussion}

Based on analyses of long-term monitoring data at South Georgia, we report significant differences in population trajectories and breeding success between wandering albatrosses in the Bay of Isles and Bird Island. The annual decline in breeding numbers at the Bay of Isles was approximately half that at Bird Island $(-1.44 \%$ vs $-3.01 \%$ per annum). This is consistent with the variability in population trends between 1984 and 2015 observed among wandering 
Table 3 Mean exponential growth rate (r) and \% annual change in population growth for colonies on Bird and Prion islands modelled using Vortex Population Viability Analysis tool and using boot-

\begin{tabular}{lllr}
\hline Colony & Breeding success & Mean r (95\% CI) & $\begin{array}{c}\text { \% Annual change in } \\
\text { population growth }\end{array}$ \\
\hline Bird island & 0.72 & $-0.0138(-0.0134,-0.0142)$ & $-1.37(-1.33,-1.41)$ \\
Prion island & 0.83 & $-0.0079(-0.0076,-0.0083)$ & $-0.79(-0.76,-0.83)$ \\
\hline
\end{tabular}

strapped estimated values for adult survival, juvenile survival and $\%$ females breeding from Pardo et al. 2017, Fig. 1 (1981-2012) albatross colonies at South Georgia (Table 2). Similarly large differences also exist between colonies of other albatross species at South Georgia (Poncet et al. 2017), and in wandering albatrosses at the Crozet Archipelago where most have increased since 1982 with the exception of Ile de l'Est (Weimerskirch et al. 2018). Based on our VORTEX population models, differences in breeding success could partly explain the differences in population growth rate, despite variance in the parameters for adult mortality, juvenile mortality and proportion of females breeding. Our model results did not fully match the observed rate of decline in breeding pairs, however, which suggests either that the 11-year dataset on breeding success at Prion Island may not be representative of earlier years or birds on Albatross Island, or that there are additional factors that also influence demographic rates.

One possible explanation for the difference in population trajectories, though very unlikely, is dispersal from Bird Island to the Bay of Isles. Wandering albatrosses generally show very high site fidelity, although they do change their nest site on average once in their lifetime, usually when they change partner (Gauthier et al. 2010). During the 2019 survey at Albatross and Prion islands, all breeding birds present at nests-half the breeding population-were checked for leg rings. Only two ringed birds were found, one originating from Bird Island and the other from Possession Island (Crozet Archipelago). Given that all chicks that fledge from Bird Island, and all breeding adults have been ringed for the last $35+$ years, rates of emigration to the Bay of Isles colonies are clearly very low. Checking all breeding birds for rings during subsequent censuses would improve data on dispersal between colonies.

The reason for the higher breeding success on Prion Island remains unclear. Extreme weather can affect breeding success in other seabirds, including black-browed albatrosses Thalassarche melanophris (Descamps et al. 2015; Cleeland et al. 2020). Human disturbance could also be a factor Carey (2009), as regular nest visits are made only at Bird Island and elsewhere are known to result in elevated heart rate of wandering albatrosses and potentially higher energy expenditure for 2 to $3 \mathrm{~h}$ after exposure (Weimerskirch et al. 2002). However, productivity at Bird Island is comparable or higher than at other colonies of great albatrosses Diomedea spp. worldwide (Cuthbert et al. 2004; Rolland et al. 2010; Jones et al. 2017). There is no indication that the weather is unusually severe or researcher disturbance is a particular problem at Bird Island. It is plausible that environmental conditions at the Bay of Isles are more benign, e.g. more sheltered from predominant westerly winds, than typical for great albatross colonies, but there are no meteorological data to confirm this hypothesis.

Another possibility is that the difference in breeding success, and indeed in other demographic parameters (adult and juvenile survival, breeding propensity) reflects the consequences of between-colony variation in foraging areas during the breeding or nonbreeding seasons. Tracking of wandering albatrosses at the Crozet Archipelago during the nonbreeding season indicated that part of the population is sedentary, their foraging areas overlapping extensively in breeding and sabbatical years, and a proportion of the population, mainly females, breed annually (Weimerskirch et al. 2015). Differences in foraging areas between breeding sites in the same island group or region have also been found in several other seabird species. The mean growth rate of blacklegged kittiwakes Rissa tridactyla differs between colonies, related to variation in environmental conditions such as sea surface temperature or in prey abundance in foraging areas, which may affect adult body condition, trip duration or provisioning rate (Frederiksen et al. 2005). In Scopoli's shearwaters Calonectris diomedea, differences in foraging areas led to spatial differences in overlap with fisheries, influencing bycatch rates and hence survival, with long-term impacts on population growth rate (Genovart et al. 2018).

Overlap of wandering albatrosses from Bird Island with diverse demersal and pelagic fishing fleets varies extensively both seasonally and among years (Jiménez et al. 2016; Clay et al. 2019). It is quite possible that wandering albatrosses from other breeding sites at South Georgia might be exposed to different fleets and hence bycatch risks, possibly with additional knock-on consequences for population age structure; this could affect age of first breeding, breeding propensity or breeding success (Froy et al. 2013).

The differences in population growth rate among sites could also be influenced by a density-dependent reduction in recruitment age, observed not only in wandering albatrosses at South Georgia, but also in other seabird species elsewhere, including black-legged kittiwakes and great skuas Stercorarius skua (Croxall 1990; Coulson 2011; Furness et al. 2015). In wandering albatrosses, there was also a 
density-dependent reduction in recruitment rate in the southern Indian Ocean, and a clear negative relationship betweencolony size and juvenile survival (Fay et al. 2015). As the age structure of the birds breeding at the Bay of Isles is unknown, it is not possible to determine whether disparities in juvenile survival or recruitment age are contributing to the difference in growth trajectory from Bird Island.

In conclusion, differences in breeding success between Bird Island and the Bay of Isles colonies only partly explain the divergent population trends. Collection of tracking and demographic data from the Bay of Isles would allow testing of other hypotheses. Tracking data would also inform the need for further marine conservation measures for the South Georgia population.

Acknowledgements We thank two referees, Rachael Herman and Tegan Carpenter-Kling, as well as the editor, Dieter Piepenburg, for their helpful comments which greatly improved our manuscript. The study was conducted using funding and support from the Government of South Georgia and the Sandwich Islands, South Georgia Surveys and British Antarctic Survey. We are very grateful to the many field workers who assisted with monitoring at the Bay of Isles and Bird Island. This study represents a contribution to the Ecosystems component of the British Antarctic Survey Polar Science for Planet Earth Programme, funded by The Natural Environment Research Council.

\section{Compliance with ethical standards}

Conflict of interest The authors have declared that no conflicts of interest exist.

Ethical approval The study was carried out under science permits approved by the Government of South Georgia and the South Sandwich Islands (GSGSSI).

Open Access This article is licensed under a Creative Commons Attribution 4.0 International License, which permits use, sharing, adaptation, distribution and reproduction in any medium or format, as long as you give appropriate credit to the original author(s) and the source, provide a link to the Creative Commons licence, and indicate if changes were made. The images or other third party material in this article are included in the article's Creative Commons licence, unless indicated otherwise in a credit line to the material. If material is not included in the article's Creative Commons licence and your intended use is not permitted by statutory regulation or exceeds the permitted use, you will need to obtain permission directly from the copyright holder. To view a copy of this licence, visit http://creativecommons.org/licenses/by/4.0/.

\section{References}

Agreement on the conservation of albatrosses and petrels (2017) Report of the populations and conservation status working group. https:// acap.aq/advisory-committee/ac10/ac10-meeting-documents/3126ac10-doc-11-pacswg-report/file. Accessed 15 Aug 2020

BirdLife International (2018) Diomedea exulans. The IUCN red list of threatened species. https://doi.org/10.2305/IUCN.UK.2018-2. RLTS.T22698305A132640680.en. Accessed 06 Oct 2020
Carey JM (2009) The effects of investigator disturbance on procellariiform seabirds: a review. NZ J of Zool 36:367-377

Clay TC, Small C, Tuck GN, Pardo D, Carneiro APB, Wood AG, Croxall JP, Crossin GT, Phillips RA (2019) A comprehensive largescale assessment of fisheries bycatch risk to threatened seabird populations. J Appl Ecol 56:1882-1893

Cleeland J, Pardo D, Raymond B, Terauds A, Alderman R, McMahon C, Phillips RA, LeaHindell MA (2020) Introduced species and extreme weather as key drivers of reproductive output in three sympatric albatrosses. Sci Rep 10:E8199

Coulson J (2011) The kittiwake. T and AD Poyser, London

Croxall JP, Rothery P, Pickering SPC, Prince PA (1990) Reproductive performance, recruitment and survival of wandering albatrosses Diomedea exulans at bird island, south Georgia. J Anim Ecol 59:775-796

Cuthbert R, Sommer E, Ryan P, Cooper J, Hilton G (2004) Demography and conservation of the tristan albatross Diomedea [exulans] dabbenena. Biol Conserv 117:471-481

Descamps S, Anker-Nilssen T, Barrett RT, Irons DB, Merkel F, Robertson GJ, Yoccoz NG, Mallory ML, Montevecchi WA, Boertmann D (2017) Circumpolar dynamics of a marine top-predator track ocean warming rates. Glob Chang Biol 23:3770-3780

Descamps S, Tarroux A, Varpe O, Yoccoz NG, Tveraa T, Lorentsen SH (2015) Demographic effects of extreme weather events: snow storms, breeding success, and population growth rate in a long-lived antarctic seabird. Ecol Evol 5:314-325

Fay R, Weimerskirch H, Delord K, Barbraud C (2015) Population density and climate shape early-life survival and recruitment in a long-lived pelagic seabird. J Anim Ecol 84:1423-1433

Frederiksen M, Edwards M, Mavor RA, Wanless S (2007) Regional and annual variation in black-legged kittiwake breeding productivity is related to sea surface temperature. Mar Ecol Prog Ser 350:137-143

Frederiksen M, Harris MP, Wanless S (2005) Inter-population variation in demographic parameters: a neglected subject? Oikos 111:209-214

Froy H, Philips RA, Wood AG, Nussey DH, Lewis S (2013) Agerelated variation in reproductive traits in the wandering albatross: evidence for terminal improvement following senescence. Ecol Lett 16:642-649

Furness RW (2015) Density dependence in seabirds: great skuas Stercorarius skua start to breed at a younger age when conditions are better. Ringing Migr 30:43-50

Gauthier G, Milot E, Weimerskirch H (2010) Small scale dispersal and survival in a long-lived seabird, the wandering albatross. J Anim Ecol 79:879-887

Genovart M, Becares J, Igual JM, Martinez-Abrain A, Escandell R, Sanchez A, Rodriguez B, Arcos JM, Oro D (2018) Differential adult survival at close seabird colonies: the importance of spatial foraging segregation and bycatch risk during the breeding season. Glob Chang Biol 41:1290-1279

Hamilton S, Moller H (1995) Can PVA models using computer packages offer useful conservation advice? Sooty shearwaters Puffinus griseus in New Zealand as a case study. Biol Conserv 73:107-117

Hunt LG, He X (2019) Seabird population dynamics. In: Cochran JK, Bokuniewicz HJ, Yager PL (eds) Encyclopedia of ocean sciences, 3rd edn. Academic Press, New York, pp 76-79

Jiménez S, Domingo A, Brazeiro A, Defeo O, Wood AG, Froy H, Xavier JC, Phillips RA (2016) Sex-related variation in the vulnerability of wandering albatrosses to pelagic longline fleets. Anim Conserv 19:281-295

Jones MGW, Dilley BJ, Hagens QA, Louw H, Mertz EM, Vissel P, Ryan PG (2017) Wandering albatross Diomedea exulans breeding phenology at Marion Island. Polar Biol 40:1139-1148 
Lacy RC, Miller PS, Traylor-Holzer K (2018) Vortex 10 user's manual. 1 June 2018 update. IUCN SSC conservation breeding specialist group, Gland, and Chicago Zoological Society, Apple Valley, Minnesota

Lacy RC, Pollak JP (2014) Vortex: a stochastic simulation of the extinction process. Version 10.0. Chicago Zoological Society, Brookfield

Mauck RA, Huntington CE, Grubb TC (2004) Age-specific reproductive success: evidence for the selection hypothesis. Evolution 58:880-885

Muggeo VMR (2008) Segmented: an R package to fit regression models with broken-line relationships. R News 8:20-25

Oro D, Torres R, Rodríguez C, Drummond H (2010) Climatic influence on demographic parameters of a tropical seabird varies with age and sex. Ecology 91:1205-1214

Pardo D, Forcada J, Wood AG, Tuck GN, Ireland L, Pradel R, Croxall JR, Phillips RA (2017) Additive effects of climate and fisheries drive ongoing declines in multiple albatross species. Proc Natl Acad Sci USA 114:E10829-E10837

Phillips RA, Gales R, Baker GB, Double MC, Favero M, Quintana F, Tasker ML, Weimerskirch H, Uhart M, Wolfaardt A (2016) The conservation status and priorities for albatrosses and large petrels. Biol Conserv 201:169-183

Poncet S, Robertson G, Philips RA, Lawton K, Phalan B, Trathan PN, Croxall JP (2006) Status and distribution of wandering, blackbrowed and grey-headed albatrosses breeding at South Georgia. Polar Biol 29:772-781

Poncet S, Wolfaardt AC, Black A, Browning S, Lawton K, Lee J, Passfield K, Strange G, Phillips RA (2017) Recent trends in numbers of wandering, black-browed and grey-headed albatrosses breeding at South Georgia. Polar Biol 40:1347-1358

R Core Team (2018) R: a language and environment for statistical computing. R Foundation for Statistical Computing, Vienna
Rolland V, Weimerskirch H, Barbraud C (2010) Relative influence of fisheries and climate on the demography of four albatross species. Glob Chang Biol 16:1910-1922

Sandvik H, Erikstad KE, Sather BE (2012) Climate affects seabird population dynamics both via reproduction and adult survival. Mar Ecol Prog Ser 454:273-284

Weimerskirch H, Delord K, Barbraud C, Le Bouard F, Ryan PG, Fretwell P, Marteau C (2018) Status and trends of albatrosses in the French southern territories, western Indian ocean. Polar Biol 41:1963-1972

Weimerskirch H, Delord K, Guitteaud A, Phillips RA, Pinet P (2015) Extreme variation in migration strategies between and within wandering albatross populations during their sabbatical year, and their fitness consequences. Sci Rep 5:8853

Weimerskirch H, Jouventin P (1987) Population dynamics of the wandering albatross, Diomedea exulans, of the crozet islands: causes and consequences of the population decline. Oikos 49:315-322

Weimerskirch H, Salamolard M, Sarrazin F, Jouventin P (1993) Foraging strategy of wandering albatrosses through the breeding season: a study using satellite telemetry. Auk 110:325-342

Weimerskirch H, Shaffer SA, Mabille G, Martin J, Boutard O, Rouanet JL (2002) Heart rate and energy expenditure of incubating wandering albatrosses: basal levels, natural variation, and the effects of human disturbance. J Exp Biol 205:475-483

Publisher's Note Springer Nature remains neutral with regard to jurisdictional claims in published maps and institutional affiliations. 